\title{
The effects of peer rejection, parent and teacher support on working memory performance: An experimental approach in middle childhood
}

\author{
Loren Vandenbroucke ${ }^{\mathrm{a}, *}$, Jantine L. Spilt ${ }^{\mathrm{b}}$, Karine Verschueren ${ }^{\mathrm{b}}$, Dieter Baeyens ${ }^{\mathrm{a}}$ \\ ${ }^{\text {a }}$ Parenting and Special Education, Ku Leuven - University of Leuven, Belgium \\ ${ }^{\mathrm{b}}$ School Psychology and Child and Adolescent Development, KU Leuven - University of Leuven, Belgium
}

\section{A R T I C L E I N F O}

\section{Keywords:}

Working memory

Peer rejection

Relational support

Parent-child relationship

Teacher-child relationship

\begin{abstract}
A B S T R A C T
Working memory performance, important for children's learning, can be influenced by social interactions. The current study investigates whether parent and teacher support buffer the negative effect of peer rejection on working memory performance, using an experimental approach. Children from third to sixth grade (aged 8-14; $n=412$ ) filled out questionnaires and completed an experiment. Working memory performance (Corsi Task Backwards) was measured at the beginning of the experiment. Next, peer rejection was manipulated (Cyberball Task), followed by a manipulation of parent and teacher support (audio message) and a posttest measure of working memory. There was no main effect of peer rejection and parent or teacher support. Social acceptance did moderate the buffering effect of teacher support for working memory performance. Teachers should be aware of the role of their relational support for children's cognition and learning.
\end{abstract}

\section{Introduction}

Working memory is a limited capacity memory system responsible for temporarily holding information in mind, while processing and manipulating that information (Baddeley, 2010). Working memory has been related to many developmental outcomes, but one area in which working memory is of particular importance is for learning at school. In the classroom, children have to perform many activities in which they have to keep information in mind while performing a complex or mentally challenging activity. Children with low performance on working memory tasks have difficulties in remembering instructions (Alloway, 2006; Alloway, Gathercole, Kirkwood \& Elliott, 2009; Gathercole, Durling, Evans, Jeffcock \& Stone, 2008; St Clair-Thompson, Stevens, Hunt \& Bolder, 2010), solving multistep tasks (Alloway, 2006; Alloway et al., 2009), paying attention during classroom activities (Alloway et al., 2009), reading and reading comprehension (Alloway, 2006; Alloway \& Alloway, 2010; De Weerdt, Desoete \& Roeyers, 2013; Vandenbroucke, Verschueren \& Baeyens, 2017b), mathematics (Alloway, 2006; Alloway \& Alloway, 2010; De Smedt et al., 2009; De Weerdt et al., 2013; Vandenbroucke et al., 2017b), and forming positive relationships with peers and teachers (De Wilde, Koot \& van Lier, 2016; McQuade, Murray-Close, Shoulberg \& Hoza, 2013).

Because of the importance of working memory for children's classroom functioning and learning, it is critical to understand what factors, especially within the classroom environment, affect working memory performance. Research has, for a long time, mainly been focusing on the natural development or maturation of working memory. More recently, evidence is accumulating that working memory performance and development does not only influence social experiences, but also can be altered by social experiences (e.g., De Wilde et al., 2016; Morrison \& Chein, 2011; Riggs, Jahromi, Razza, Dillworth-Bart \& Mueller, 2006; Vandenbroucke, Spilt, Verschueren \& Baeyens, 2017a). Specifically, positive social interactions with peers, teachers and parents may promote working memory, while negative interactions with these important social actors may hinder working memory. Despite the growing evidence on the role of social experiences in working memory performance and development, studies examining this topic are scarce and often correlational in nature. The current study investigates the effects of social experiences with peers, parents and teachers on working memory performance adopting an experimental approach.

\subsection{Peer experiences and working memory}

Especially from middle childhood onwards, relationships with peers become increasingly important and complex. As children move from early childhood to middle childhood, they interact with larger groups of peers. Additionally, focus shifts from simple play to complex, organized, and rule oriented play and eventually to interactions based on communication (Fabes, Martin \& Hanish, 2009; Holmes, Kim-Spoon \& Deater-Deckard, 2016). Evidence is now accumulating that social

\footnotetext{
* Corresponding author at: Leopold Vanderkelenstraat 32 - Box 3765, 3000 Leuven, Belgium.

E-mail address: loren.vandenbroucke@kuleuven.be (L. Vandenbroucke).
} 
experiences with peers also have an impact on children's cognitive performance and development. One reason for this is that negative social experiences, such as peer rejection, cause stress. Stress has been shown to negatively impact executive functioning and working memory, potentially because prefrontal brain regions (related to working memory performance) work less optimally when under stress (e.g., excessive release of dopamine and cortisol in prefrontal cortex; Diamond \& Ling, 2016; Evans \& Schamberg, 2009). Other researchers suggest that stressful social contexts increase the loading on executive functioning and working memory (De Wilde et al., 2016; Williams, 2009). For example, children who are rejected will attempt to restore the relationship, which will require energy and cognitive resources. Consequently, negative social experiences occupy cognitive resources, which cannot be invested in other cognitive tasks.

Indirect evidence comes from studies linking negative experiences with peers, such as being rejected, to brain regions related to executive functioning and working memory, such as the anterior cingulate cortex and prefrontal cortex (Kim, Kroger, Calhoun \& Clark, 2015; Lenartowicz \& McIntosh, 2005; Will, van Lier, Crone \& Güroğlu, 2016). Studies directly linking peer experiences to working memory performance are now also accumulating. Observational studies using a crosslagged design showed mixed-results depending on the social outcome measured (Holmes et al., 2016; De Wilde et al., 2016). Because these studies are observational in nature, it is difficult to draw conclusions about the causality of these effects. Three experimental studies examined the effect of peer rejection on children's cognitive performance and working memory. They found that some children's cognitive performance is more affected by social experiences compared to other children. A study by Tobia, Riva and Caprin (2017) showed that children who were less accepted by peers or had lower self-esteem were more negatively affected by social exclusion on a reasoning task. This suggests that children who may feel less confident in social situations are more affected by negative social interactions. Hawes et al. (2012) found that girls who were excluded performed worse on working memory tasks than girls who were not excluded, but such an effect was not found for boys. Finally, in an experimental study with a pre-posttest design no effects of social exclusion on working memory performance were found. The current study uses a pre-posttest design to examine changes in working memory performance after an experience of social exclusion in in a sample of older children (Vandenbroucke et al., 2017a). Extending this experimental design to older children would provide important insights into the causal effects of peer relationships on working memory performance in an age group where peers start to become more central in children's social context.

\subsection{The role of support of significant adults}

Parents and teachers form attachment figures for children, providing primary sources of support (Roorda, Koomen, Spilt \& Oort, 2011). Although peer relationships become more important in middle childhood, interactions and relationships with parents and teachers remain significant factors in children's social life. Children still spend a lot of time interacting with parents and teachers and although the relationship quality with these significant adults generally decreases, research has shown that this relationship quality still predicts developmental outcomes in older children and adolescents (e.g., Hazel, Oppenheimer, Technow, Young \& Hankin, 2014; Roorda et al., 2011). Yet, research examining parent-child and teacher-child interactions and relationships in relation to cognition and working memory has focused mainly on preschool-aged children. For example, maternal sensitivity, mind mindedness and maternal autonomy support at 12 months of age predicted executive functioning, including working memory performance, at 18 to 26 months of age (Bernier, Carlson \& Whipple, 2010). A meta-analysis of studies with children younger than 8 years of age shows that positive parenting behaviors and cognitive stimulation by the parents predict better working memory (Valcan, Davis \& Pino-
Pasternak, 2017). Similarly, positive or negative relationships with teachers have been found to relate to young children's working memory performance. When the teacher-child relationship was characterized by open and warm communication, children performed better on working memory tasks (Commodari, 2013; De Wilde et al., 2016). On the other hand, high teacher-child conflict was related to lower working memory performance (De Wilde et al., 2016). To our knowledge, no studies have examined influences of parents and teachers on older children's working memory. Yet, a meta-regression analysis suggests that the strength of the effect of positive and negative parent behaviors on general executive functioning does not decline for children moving into middle childhood at the age of 8 (Valcan et al., 2017). This suggests that at least parental support might still be relevant for working memory performance of older children, though evidence is limited and, to our knowledge, not available for teacher influences.

As is the case with negative peer relationships, negative parent-child and teacher-child relationships may hinder working memory performance due to heightened stress. Positive interactions with adults who form important attachment figures could buffer against this stress (e.g., Ahnert, Harwardt-Heinecke, Kappler, Eckstein-Madry \& Milatz, 2012). As peer rejection might have a negative effect on working memory due to stress and positive interactions with parents and teachers may buffer stress, support from parents and teachers might counteract the negative effect of peer rejection on working memory performance. This idea is supported by previous studies showing that teachers can buffer negative impacts of peer rejection on children's socio-emotional functioning (e.g., Spilt, van Lier, Leflot, Onghena \& Colpin, 2014). Such an effect has, to our knowledge, not yet been examined for children's cognitive functioning or working memory performance.

The studies mentioned above are all observational in nature. Experimental studies would provide more compelling evidence on the causality of this relationship. Two studies have previously used such an approach to examine the effect of parents and teachers on children's cognition. One study found that children who had a close relationship with their teacher solved cognitive tasks faster after they had been primed with a picture of their teacher (Ahnert, Milatz, Kappler, Schneiderwind \& Fisher, 2013). However, this study examined only the effect of the teacher and used general cognitive measure, while it did not specifically focus on EFs. Similarly, another experimental study, in Grades 1 and 2, showed that when children had a negative relationship with their primary caregiver, they performed better on a working memory task after hearing a supportive audio message from their teacher, while they performed worse after hearing a supportive audio message of their primary caregiver (Vandenbroucke et al., 2017a). This study thus gives a first indication of a causal effect of parent and teacher support, though this effect depends on (parent-child) relationship quality. However, this study did not include any general measure on children's feelings of social acceptance. Based on theory and previous research, it is likely that a single moment of relational support will not be very effective when the child has a general negative idea about social interactions, since the support will not be in line with the beliefs of the child and may thus not be interpreted in such a positive way (Dykas \& Cassidy, 2011). Similarly, children who in general do not feel socially accepted (by peers or other social partners) will develop negative ideas about their self and social interactions (e.g., less trust in others) and are less likely to accept support from a parent or teacher (Gorrese \& Ruggieri, 2013; Mishna et al., 2016). The current study would provide greater insights into these processes for children in middle childhood.

\subsection{The current study}

In sum, children's interactions with peers, parents and teachers are likely to shape their working memory performance and development. Nevertheless, the number of studies on these topics are limited and often use a correlational design, making it difficult to conclude that negative (or positive) social experiences cause decreases (or increases) 
in working memory performance. Moreover, parent and teacher influences on executive functioning and working memory are almost exclusively studied in young children, while little is known about such processes in middle childhood.

The main aim of the current study was to experimentally investigate the effect of parent and teacher support on children's working memory performance, after an experience of peer rejection, in children from third to sixth grade. An experimental approach was used, with working memory measured at the beginning and end of the experiment, an experimental manipulation of peer rejection for all children and a between-subject manipulation of support by the parent or teacher. Specifically, the following research question was addressed: Does a supportive message from a parent or the teacher buffer the negative effect of social exclusion on working memory? First, it was expected that children from third to sixth grade would decrease in working memory performance after experiencing peer exclusion in an online game (De Wilde et al., 2016; Holmes et al., 2016). Second, it was expected that when children heard a supportive message of their parent or teacher after an experience of social exclusion, there would be no decrease in working memory performance (Valcan et al., 2017; Vandenbroucke et al., 2017a). In other words, parent and teacher support were assumed to buffer the negative effects of peer rejection. It was expected that a supportive message would only be strong enough when it came from important attachment figures, such as the parent and teacher, but that a supportive message from a stranger would not be sufficient to show a positive effect. The support from a stranger was thus an additional control condition to assure that the positive effect was only visible in the case of support from a familiar adult. Finally, it was investigated whether perceived social competence, parent support and conflict and teacher support and conflict moderated the effect of a supportive message from the parent or teacher. For children who feel less socially accepted, there might be a more pronounced effect of parent or teacher support because they might feel more rejection after the social exclusion (Tobia et al., 2017) and thus have more room for improvement. On the other hand, because the supportive message is perhaps not in line with what they expect (as they feel less socially excepted), it is also possible that the parent and teacher support has less effect on these children. Finally, it is expected that the supportive message of the parent or teacher will have more effect when children have a more positive relationship with that parent or teacher (Dykas \& Cassidy, 2011; Vandenbroucke et al., 2017a).

\section{Method}

\subsection{Participants}

Children from third to sixth grade were recruited through regular elementary schools in Flanders. Schools were asked to participate and those that agreed gave information and consent forms to the parents in the participating classrooms. Schools, teachers and parents were told that the study would examine the negative effects of social exclusion and positive effects of parent and teacher support on children's cognitive performance. Teachers from 31 classrooms in seven schools participated in the study. In total 492 children and their parents gave written informed consent for participation in the study $(70.5 \%$ of contacted children). Due to time constraints the experimental session of 79 children could not be scheduled and one child withdrew from the study during the experimental session, resulting in a final sample of 412 children $(83.7 \%)$.

Boys and girls were approximately equally represented in the sample ( $48.7 \%$ boys). Age ranged between 8 years and 2 months and 14 years and 1 month $(M=10.49, S D=1.15)$. Most of the children were aged between 8 and 12 . Only 5 children were older than 12 years. However, removing them from the sample did not change the results of the analyses and they were therefore not excluded from the sample. Table 1 presents the distribution of children's demographic
Table 1

Distribution of children's demographic characteristics in the sample $(n=412)$.

\begin{tabular}{lll}
\hline & $n$ & $\%$ \\
\hline $\begin{array}{l}\text { Educational level primary caregiver } \\
\text { At least a Bachelor's degree }\end{array}$ & 249 & \\
Occupational status of primary caregiver & & 65.4 \\
$\quad$ Working $\geq 75 \%$ & 246 & 63.9 \\
Working $<$ 75\% & 77 & 20.0 \\
Not working, voluntary & 40 & 10.4 \\
Not working, involuntary & 22 & 5.7 \\
Monthly net family income & & \\
$<1000$ euros & 1 & 0.3 \\
1000-2000 euros & 38 & 10.7 \\
2000-3000 euros & 66 & 18.5 \\
3000-4000 euros & 119 & 33.4 \\
4000-5000 euros & 89 & 25.0 \\
$>$ 5000 euros & 43 & 12.1 \\
Mother tongue & & \\
Monolingual Dutch speaking & 371 & 94.6 \\
Bilingual Dutch speaking & 5 & 1.2 \\
Other languages & 16 & 4.1 \\
Child with Belgian nationality & 376 & 90.8 \\
\hline & & \\
\hline
\end{tabular}

characteristics. The sample is representative for the population in Belgium with respect to employment rates (in the population: $5.1 \%$ unemployment, 73.3\% employment; Eurostat 2015), though there are more highly educated primary caregivers in our sample (in the population: 37.2\%; Eurostat 2015) and most families had a higher than average net monthly income (in the population: 2689.58 euros; Statistics Belgium, 2014). The study included a community sample. For 368 children no mental disorders were reported by the parents, for 23 children a diagnosis was reported, including selective mutism $(n=1)$, dyslexia $(n=9)$, dyscalculia $(n=1)$, ADHD $(n=5)$, ASD $(n=4)$, ADHD and dyspraxia $(n=1)$, and ADHD and ASD $(n=2)$. Five children were taking medication with methylphenidate. Results were the same when these children were left out the sample.

\subsection{Instruments}

\subsubsection{Questionnaires}

2.2.1.1. Demographics. Parents reported on background characteristics of the participating child and their family. Information was requested about the caregivers' educational level and occupational status, monthly net income, the physical and psychosocial health and medication use of the participating child, and the nationality and mother tongue of the participating child. Educational level was coded as low (i.e., a degree of secondary education at most) or high (i.e., at least a Bachelor's Degree). Occupational status was recoded into fulltime working (i.e., working at least $75 \%$ ), part time working (i.e., working $<75 \%$ ), voluntarily not working (i.e., housewife or houseman, on pension, maternity leave and temporary career breaks for $>3$ months) and involuntarily not working (i.e., in search of employment or unfit for work). Family monthly net income was categorized as below 1000 euros, between 1000 and 2000 euros, between 2000 and 3000 euros, between 3000 and 4000 euros, between 4000 and 5000 euros and above 5000 euros.

2.2.1.2. Perceived social acceptance. The social acceptance subscale of the Dutch Perceived Competence Scale for Children (Harter, 1982; Veerman, Straathof, Treffers, van den Bergh \& ten Brink, 2004) was used as an indication of the extent to which children feel accepted by their peers. The scale consisted of six items. For each item the child first had to choose which of two statements represented their beliefs best (e.g., 'Some children find it hard to make friends' and 'other children find it quite easy to make friends'). The child then chooses whether this statement was somewhat true for them or very true for them. This results in four response options (e.g., 'finding it very hard to make 
friends', 'finding it somewhat hard to make friends', 'finding it somewhat easy to make friends', and 'finding it very easy to make friends'). A score of 1 to 4 was given to each item, with a score of 1 indicating low levels of perceived social acceptance and a score of 4 indicating high levels of perceived social acceptance. The scores were averaged across all items to form a total score. Cronbach's alpha was acceptable $(\alpha=0.75)$.

2.2.1.3. Parent-child and teacher-child relationship quality. The Dutch version of the Child Relationship Questionnaire - Revised (De Laet et al., 2015; Hughes, 2011) was used to measure the quality of the parent-child and teacher-child relationship. The child had to evaluate 21 statements on the quality of the relationship with both the parent and teacher on a 5-point Likert-scale ranging from 1 (almost never) to 5 (almost always). Scores on a support scale and a conflict scale were calculated by averaging the scores on the respective items. The support scale consisted of 15 items (e.g., 'How satisfied are you with your relationship with ...?' or 'How much does ... really care about you?'). The conflict scale consisted of 6 items (e.g., 'How much does ... punish you?'). Internal consistency of both scales was good, with a Cronbach's alpha of 0.88 for parent support, 0.84 for parent conflict, 0.92 for teacher support and 0.84 for teacher conflict. This is similar to previous studies (De Laet et al., 2015).

\subsubsection{Experimental session}

2.2.2.1. Working memory. Working memory was measured with the backwards version of the Corsi Block Test (Milner, 1971). The task was administered in a one-on-one interaction between the child and the researcher (not by means of a computer). A standardized procedure was used. After the researcher tapped a series of blocks on a board with nine irregularly spaced blocks, the child had to repeat the sequence in the reverse order. If children correctly recalled four series of the same difficulty, that difficulty was increased with one additional block to remember. The test was ended if the child incorrectly recalled three series of the same difficulty. The child received a maximum of six items of the same difficulty. A working memory score was calculated as the number of sequences correctly reversed. Higher scores indicate better working memory performance. Two sets of items were used (Alloway, 2007; Gathercole \& Pickering, 2000). The order of both sets was counterbalanced. Careful analysis of the items indicated that both sets should be equally difficult (Busch, Farrell, Lisdahl-Medina \& Krikorian, 2005). This was confirmed by an independent samples $t$-test indicating that average scores of both sets did not differ at pre-test $(\mathrm{t}$ $(410)=-0.31, p=.755)$. This indicates both versions could be considered as parallel versions and order was not controlled for in further analyses.

2.2.2.2. Social rejection. Social rejection was manipulated with the cyberball paradigm (Williams et al., 2000; Vandenbroucke et al., 2017a). Children were told they were playing an online ball tossing game with two other people of their age and that they had to imagine they were playing the game in real life. They were told the two other children were also participating, but in another school. In reality the game was programmed and the two other people did not exist. Children were included during the first 18 throws in the game and excluded by the two (fictive) players during the last 20 throws. A name was given to the two fictive players (one boy's name and one girl's name). After the game, children indicated how often they received the ball from the other players (never, sometimes, often or always) as a manipulation check. At the end of the experiment the child played an inclusion version of the game, for ethical reasons. The child was also told about the deception when the experimental session was finished. Cyberball is a validated measure of social exclusion, known to cause mild distress and increased physiological arousal (Abrams, Weick, Thomas, Colbe \& Franklin, 2011; Kelly, McDonald \& Rushby, 2012; Van Noordt, With, Wu, Mayes \& Crowley, 2015), and has previously been shown to negatively impact working memory performance in children (Hawes et al., 2012).

2.2.2.3. Parent and teacher relational support. Relational support offered by parents and teachers was manipulated through an audio message. Children heard one of four audio messages: a weather report (control condition), a supportive message from a stranger (control condition), a supportive message from the primary caregiver and a supportive message from the teacher. A supportive message from a known adult activates the attachment system of the child, which, in case of a positive relationship, is expected to positively impact children's cognition (Ahnert et al., 2013; Seltzer, Ziegler \& Pollak, 2010). Before the start of the audio message children were informed they would hear an audio message and they had to listen to what was said carefully. If the audio message was from a parent or teacher this was mentioned to make sure the children would recognize the voice. The content of the supportive messages was standardized (Appendix A) and recorded before the start of the experiment. All audio messages lasted approximately $30 \mathrm{~s}$. A blocked randomization was used for assigning children to the four conditions, to ensure that conditions were equally divided over schools, classrooms and gender (Suresh, 2011). After hearing the audio message, the child indicated how much he or she liked hearing the message on a scale from 1 (not at all) to 5 (very much).

\subsection{Procedure}

This study was approved by the Ethics Committee of social and societal ethics committee of KU Leuven. Data was collected by the first author and graduate students in Psychology and Educational Sciences. Before the start of the study, parents were asked who could be considered the primary caregiver of the participating child. This was the parent about who the child filled out the questionnaires and this was the parent who recorded the audio message in the parent support condition. This way it was assured that in the parent support condition, children filled out the questionnaire about the parent from who they also heard the voice. The audio messages were also recorded before the start of the study. The parents and teachers received the text of the message from the researcher. They either recorded the message themselves or they were contacted by telephone and the message was recorded through an app on the researchers' smartphone. The quality of all recordings was checked before use in the study. The study consisted of two parts. First, the questionnaires were administered in the classroom of the children. A researcher read the instructions out loud for each questionnaire. For the younger children (third and fourth grade) all items were also read out loud. The older children (fifth and sixth grade) could fill out the questionnaires at their own pace. The researcher provided clarification to the child if needed. Second, the experiment with a pre-posttest between-subjects design was conducted during an individual session with the child. Working memory was measured at the beginning of the experiment. Then the social exclusion game (cyberball) was played by the child and, shortly after the game, the child heard one of the audio messages (weather report, supportive message of stranger, supportive message of parent, supportive message of teacher). Finally, working memory was measured again and children finished with an inclusion version of the game. At the end children were debriefed and received a small age appropriate gift for their participation.

\subsection{Analytical plan}

All analyses were conducted in IBM SPSS statistics 24 (IBM Corp., 2016). Descriptive statistics were examined for all study variables. Three preliminary analyses were conducted. First, the distributions of child characteristics (age, grade, parent educational level, parent work status, family income) and study variables (perceived social acceptance, parent support and conflict, teacher support and conflict) across the 
conditions were examined. To examine differences between conditions in child characteristics, one-way ANOVA and chi-square tests were used. To examine differences between conditions in the study variables, one-way ANOVAs were performed. Second, manipulation checks (on how often children say to have received the ball and how well they liked the audio message) were examined in order to see if the manipulations had the expected effect. Finally, it was examined whether any of the child background characteristics was related to working memory scores at the beginning of the experiment. To this end, Pearson correlation (age), Spearman correlations (grade, family income), $t$-test (educational level of primary caregiver) and one-way ANOVA (work status of primary caregiver) were used.

In order to answer the main research questions, it was examined whether multilevel analyses were suitable for the present data. Because there was significant child level variability in working memory ( $\sigma=14.44 ; 95 \%$ CI $[12.40 ; 16.49], p<.001)$, but non-significant classroom level variance ( $\sigma=1.42 ; 95 \%$ CI $[-0.04 ; 2.88], p=.056)$ and school level variance ( $\sigma=0.50 ; 95 \%$ CI $[-0.71 ; 1.70], p=.420$ ), repeated measure ANOVAs were conducted. Working memory score was used as within-subject variable and condition was used as betweensubject variable. Effects of parent and teacher support were investigated by comparing the change in working memory between the four conditions. Perceived social acceptance, parent support, parent conflict, teacher support and teacher conflict were added as moderators as (continues variables) in order to examine whether the effect of a supportive message depended on one or more of these variables. To examine potential moderation, the interactions between time, condition and each of the moderators was added in the analyses (e.g., time $\times$ condition $\times$ parent support). When these interactions are significant, it indicates that the difference between the conditions in working memory change depends on the moderator included in the interaction. Analyses were controlled for relevant background characteristics of the participants. Additionally to examining the four conditions separately, contrast was tested. In a first contrast it was tested whether there was a difference between the two control conditions. Then the effect of the parent support condition compared to the two control conditions was examined. The same was done for teacher support.

\section{Results}

\subsection{Descriptive statistics}

Table 2 displays the means and standard deviations of the study variables and the correlations between the study variables. In general, high levels of perceived social acceptance were reported in the current sample. The relationship with the primary caregiver was characterized by high levels of support and low to moderate levels of conflict. The teacher-child relationship was characterized by moderate levels of support and low levels of conflict. Children with higher perceived social acceptance reported more parent support and less parent conflict. The variables measuring the quality of the parent-child and teacher-child relationship were low to moderately related to each other.

Table 3 shows the descriptive statistics of the outcome working memory across the four conditions. Pre-experiment levels of working memory were slightly lower in the weather report condition and slightly higher in the parent support condition. Yet, this difference was not statistically significant $(F(3,411)=1.43, p=.234)$.

\subsection{Preliminary analysis}

First, differences between the conditions at the beginning of the experiment were examined for a number of child characteristics (age, grade, gender, educational level of primary caregiver, work status of primary caregiver and family income) and the study variables (perceived social acceptance, parent support and conflict, teacher support). All child characteristics, age $(F(3,388)=0.37, p=.778)$, grade $\left(\chi^{2}=1.15, d f=9, p=.999\right)$, gender $\left(\chi^{2}=0.60, d f=3, p=.869\right)$, educational level of the primary caregiver $\left(\chi^{2}=1.07, d f=3\right.$, $p=.784)$, work status of the primary caregiver $\left(\chi^{2}=9.77, d f=9\right.$, $p=.370)$, and family income $\left(\chi^{2}=14.63, d f=15, p=.478\right)$, were equally distributed across conditions. This indicates the randomization across conditions was successful. Additionally, perceived social acceptance $(F(3,408)=0.53, p=.660)$, parent support $(F(3,409)=0.68$, $p=.567)$, parent conflict $(F(3,409)=1.20, p=.309)$, and teacher support $(F(3,409)=1.05, p=.369)$ did not differ between conditions at the beginning of the experiment. Teacher conflict did significantly differ between the conditions at the beginning of the experiment, with children in the teacher support condition reporting higher levels of teacher conflict $\quad\left(M_{\text {WeatherReport }}=1.33, \quad S D_{\text {WeatherReport }}=0.47\right.$, $M_{\text {StrangerSupport }}=1.36, \quad S D_{\text {StrangerSupport }}=0.52, \quad M_{\text {ParentSupport }}=1.38$, $S D_{\text {ParentSupport }}=0.47, M_{\text {TeacherSupport }}=1.60, S D_{\text {TeacherSupport }}=0.80, F(3$, $407)=4.794, p=.003$ ). This should be taken into account when interpreting results.

Second, manipulation checks were examined. When asked how often they received the ball, most children indicated they received the ball sometimes $(n=362)$. Some children indicated they received the ball often $(n=30)$ or never $(n=20)$. As none of the children indicated they always received the ball, we can assume that the children understood the game and were paying attention to it. With regard to the audio messages, children indicated the weather report was very much liked (4.0\%), liked (18.8\%), neutral (64.4\%), not liked (10.9\%), or not liked at all (2.0\%). The supportive message from the stranger was very much liked (17.1\%), liked (52.4\%), or neutral (30.5\%). The supportive message of the parent was rated as very much liked (55.6\%), liked (30.3\%) or neutral $(14.1 \%)$. Finally, the supportive message from the teacher was experienced as very much liked (36.4\%), liked (45.8\%), or neutral $(16.8 \%)$. The differences between the audio messages were significant $\left(\chi^{2}=161.00, d f=12, p<.001\right)$, indicating that, as expected, the supportive messages of the parents and teachers were

Table 2

Mean and standard deviations of all study variables and correlations between study variables $(n=409-412)$.

\begin{tabular}{|c|c|c|c|c|c|c|c|c|}
\hline & $M(S D)$ & Min-Max & 1. & 2. & 3. & 4. & 5. & 6. \\
\hline 1. Social acceptance & $3.11(0.62)$ & $1.00-4.00$ & & & & & & \\
\hline 2. Parent support & $3.96(0.61)$ & $1.73-5.00$ & $.12^{*}$ & & & & & \\
\hline 3. Parent conflict & $1.87(0.71)$ & $1.00-5.00$ & $-.16^{* *}$ & $-.39^{* * *}$ & & & & \\
\hline 4. Teacher support & $3.08(0.76)$ & $1.00-5.00$ & .08 & $.31^{* * * *}$ & -.05 & & & \\
\hline 5. Teacher conflict & $1.42(0.59)$ & $1.00-5.00$ & -.04 & $-.14^{* *}$ & $.31^{* * *}$ & $-.34^{* * * *}$ & & \\
\hline 6. WM pre & 21.15 (4.07) & $8.00-30.00$ & .07 & .03 & -.08 & -.04 & -.08 & \\
\hline 7. WM post & $20.68(4.44)$ & $8.00-35.00$ & .09 & .03 & -.09 & -.02 & .01 & $.57^{\text {***** }}$ \\
\hline
\end{tabular}

$\mathrm{WM}=$ working memory.

${ }^{*} p<.05$.

*** $p<.01$.

*** $p<.001$. 
Table 3

Descriptive statistics of the outcome variable working memory at the start and end of the experiment across the different conditions $(n=412)$.

\begin{tabular}{|c|c|c|c|c|c|c|c|c|}
\hline & \multicolumn{4}{|c|}{ Pre-test working memory } & \multicolumn{4}{|c|}{ Post-test working memory } \\
\hline & Min & $\operatorname{Max}$ & $M$ & $S D$ & Min & $\operatorname{Max}$ & $M$ & $S D$ \\
\hline Weather report $(n=101)$ & 8 & 30 & 20.54 & 4.54 & 8 & 31 & 20.33 & 4.64 \\
\hline Stranger support $(n=105)$ & 12 & 30 & 21.11 & 3.99 & 8 & 35 & 20.58 & 4.44 \\
\hline Parent support $(n=99)$ & 12 & 30 & 21.73 & 3.84 & 13 & 35 & 21.19 & 4.70 \\
\hline Teacher support $(n=107)$ & 12 & 30 & 21.21 & 3.83 & 12 & 31 & 20.62 & 4.03 \\
\hline
\end{tabular}

experienced as more enjoyable than the supportive message from the stranger, which was experienced as more enjoyable than the weather report.

Finally, the relationships between children's background characteristics and working memory scores at the beginning of the experiment were investigated. Age $(r=0.26, p<.001)$, grade $(r=0.29$, $p<.001)$, educational level of primary caregiver $(t(379)=2.02$, $p=.044)$, and work status of the primary caregiver $(F(3,384)=2.89$, $p=.035$ ) were significantly related to working memory. Older children or children in higher grades, and children with a highly educated primary caregiver had higher working memory scores. Children of a fulltime working primary caregiver had higher working memory scores compared to children of unemployed primary caregivers. Family income was not significantly related to working memory scores $(r=0.07$, $p=.16)$. Since age and grade were highly related $(r=0.93, p<.001)$ and more data was available for grade, grade (and not age) was added as a control variable in further analyses in addition to educational level and work status.

\subsection{The effect of parent and teacher support}

The change in working memory was compared between the four conditions (weather report, stranger support, parent support, teacher support) in order to investigate the effect of parent and teacher support. Table 4 provides the results of the repeated measures ANOVA. Working memory remained stable from pre- to post-test. The interaction between working memory and condition was not significant, indicating that the change in working memory was the same for the control conditions and the parent and teacher support conditions. The interactions between time, condition and the relationship variables (perceived social acceptance, parent support, parent conflict, teacher support, and teacher conflict) were also non-significant, indicating that none of these variables moderated the effect of condition on change in working memory performance.

\subsection{Contrasts}

Contrasts were tested to examine the potential effect of parent

\section{Table 4}

Repeated measures ANOVA with working memory as within-subject factor, condition as between-subject factor and social acceptance, parent support, parent conflict and teacher support as covariates.

\begin{tabular}{lllll}
\hline & \multicolumn{4}{l}{ Working memory } \\
\cline { 2 - 5 } & $F$ & $d f$ & $p$ & $\eta_{\text {partial }}^{2}$ \\
\cline { 2 - 5 } & & & & \\
Time & 1.76 & 1351 & .185 & 0.005 \\
Time $*$ condition & 0.69 & 3351 & .559 & 0.006 \\
Time $*$ condition $*$ social acceptance & 2.45 & 3351 & .063 & 0.021 \\
Time $*$ condition $*$ parent support & 0.70 & 3351 & .554 & 0.006 \\
Time $*$ condition $*$ parent conflict & 1.48 & 3351 & .219 & 0.013 \\
Time $*$ condition $*$ teacher support & 0.84 & 3351 & .475 & 0.007 \\
Time $*$ condition $*$ teacher conflict & 0.79 & 3351 & .501 & 0.007
\end{tabular}

Note. All analyses are controlled for educational level of primary caregiver, occupational status of primary caregiver and grade. support (in contrast to the control conditions) and teacher support (in contrast to the control conditions) separately. First, the difference between the two control conditions (weather report and stranger support) was tested, to see whether these could be treated as one group. As expected, there was no main effect of condition $(F(1,168)=0.03$, $\left.p=.873, \eta_{\text {part }}^{2}<0.001\right)$ and no interaction effect with any of the moderators $(p=.117-.976)$. Thus, these two conditions were combined when testing further contrasts. Second, the difference between parent support and the control condition (weather report and stranger support taken together) was tested. Again, no significant results were found, both with regard to the main effect of condition $(F(1,260)=1.15$, $\left.p=.284, \eta_{\text {part }}^{2}=0.004\right)$ and the interactions with the moderators ( $p=.171-.718)$. Finally, the teacher support condition was compared to the control condition (weather report and stranger support taken together). A significant time $\mathrm{x}$ condition $\mathrm{x}$ social acceptance was found $\left(F(1,271)=7.44, p=.007, \eta_{\text {part }}^{2}=0.027\right)$. The effect was large. To interpret the meaning of this interaction, the parameter estimates of the model were used to calculate the pre- and post-test working memory scores in the two groups for different levels of perceived social acceptance, while the scores of the control variables and other moderators were held constant. This is displayed in Fig. 1. The figure shows that for intermediate levels of perceived social acceptance (scores of 2 or 3 ) working memory performance remains relatively stable, irrespective of condition. In case of low social acceptance, children in the teacher support condition decrease in working memory performance, while children in the control conditions show little change in working memory performance. For children who score at the high end of the perceived social acceptance scale, teacher support seems to have a positive effect, while working memory performance is stable in the control conditions.

\section{Discussion}

The current study aimed to investigate the effect of negative interactions with peers and supportive interactions with parents and teachers on working memory performance in middle childhood. The experimental paradigm used in this study was already included in a study with younger children, where effects of parent and teacher support were found (Vandenbroucke et al., 2017a). Although no general effect was found of peer rejection and parent and teacher support in the current study, teacher support did have a negative effect for children with low levels of perceived social acceptance and an enhancing effect for children with high levels of perceived social acceptance.

\subsection{Parent and teacher support and working memory}

No general protective effect of parent and teacher support on working memory performance was found in the current sample. This is contrast to what we expected based on other studies showing that positive interactions with important adults are associated with higher working memory performance (Valcan, Davis \& Pino-Pasternak, 2017; Vandenbroucke, Spilt, Verschueren, Piccinin \& Baeyens, 2018). It is possible that cognitive tasks, such as the working memory task used in this study, are not affected by one single occasion of support, but rather are affected by social interactions on the long term. Long term social 


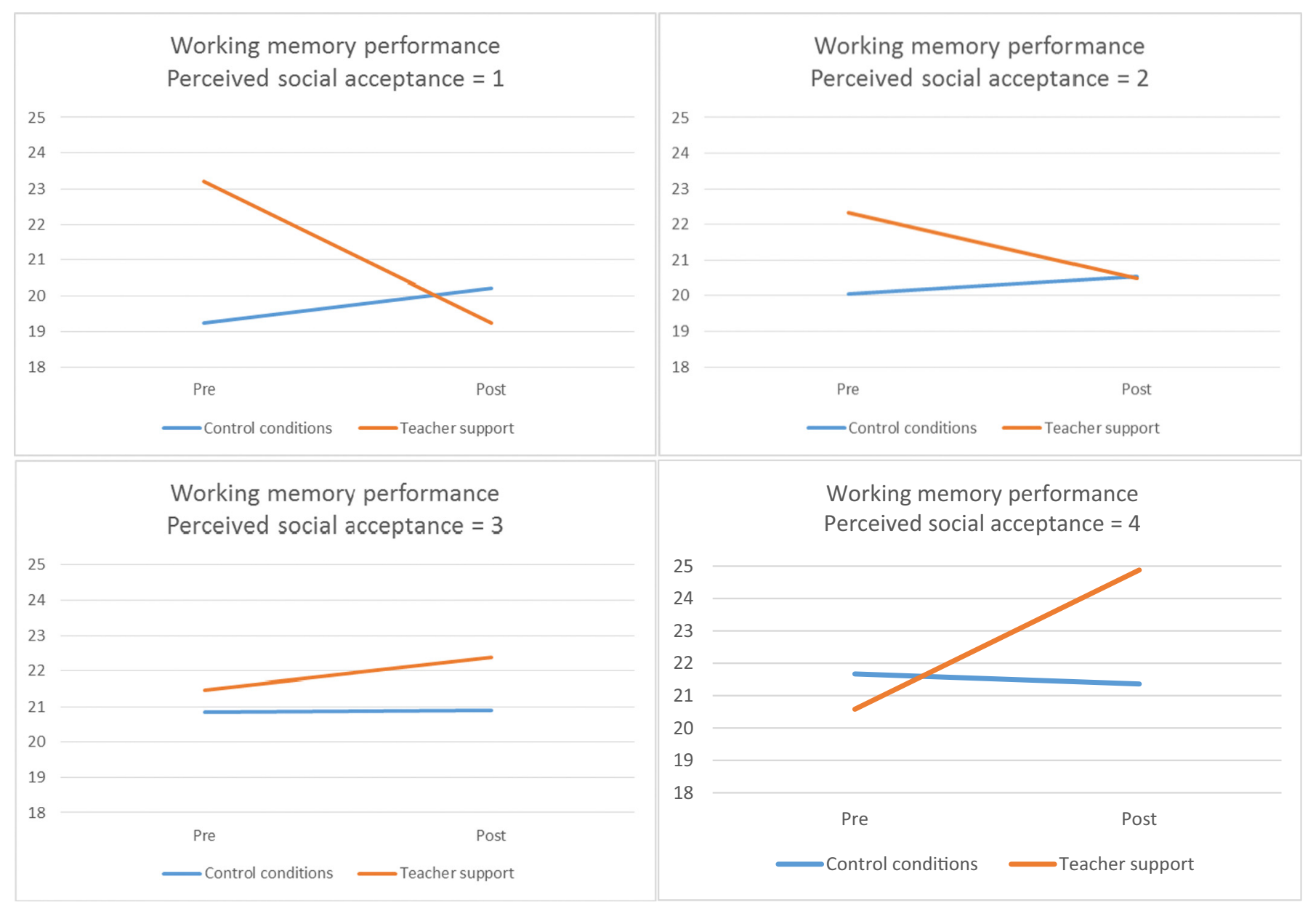

Fig. 1. Working memory scores at pre- and post-test in the control conditions $(n=183)$ and the teacher support condition $(n=103)$ for different levels of perceived social acceptance.

exclusion and negative interactions with parents or teachers may lead to chronic stress (e.g., Ahnert et al., 2012; Lafko, Murray-Close \& Shoulberg, 2015) impeding children's working memory, or children may withdraw (De Wilde et al., 2016; Williams, 2009) exposing them less to challenging activities in which they can practice working memory skills. However, alternative explanations for the lack of this negative result should also be considered. One alternative explanation is that the interaction with the researcher during the rest of the experimental session may have lifted the negative effect of the peer exclusion. This interaction was standardized and neutral in nature (no specific positive remarks were given to the participant), but it could have provided a distraction from the negative experience of the social exclusion and diminish its effects. Another possibility is that an effect on working memory performance is not visible due to a learning effect. Because the two versions of the working memory task were administered approximately $30 \mathrm{~min}$ apart, children might have experienced a learning effect, which was equaled out by the negative effect of the social exclusion. In order to examine such processes, a condition without social exclusion should be added. This way the change in working memory at the beginning and end of the experiment can be compared for children who do and who do not experience peer exclusion.

Interestingly, when examining the effect of parent and teacher support separately, it was found that for some children teacher support after social peer exclusion did affect working memory performance. Specifically, children who perceived themselves as not well accepted by others performed worse after they heard a supportive message from the teacher after being excluded in comparison to excluded children who received a neutral audio message or a message from a unfamiliar person. For children who perceived themselves as highly accepted, results suggested a positive effect of teacher support. It is possible that children who do not feel socially accepted may be more negatively oriented toward social interactions and interpreted the supportive message from the teacher more negatively (e.g., 'the teacher is just saying that because she has to' or 'she does not really mean that'). This is in line with research showing an association between children's perceived social acceptance and secure base script knowledge (e.g., Psouni, Di Folco \& Zavattini, 2015). Children who feel less accepted do not believe that they are worthy of care and they think their caregiver (e.g., the teacher) will not be available when they need them or will not support them adequately. The fact that the current study showed an effect of teacher support for some children, but not others, nuances existing insights showing that supportive and warm interactions with teachers promote working memory (Commodari, 2013; De Wilde et al., 2016; Valcan et al., 2017). However, while these previous studies examined the association between the general relationship quality and working memory, the current study provided an examination of the immediate effect of one moment of relational support. Additionally, this study shows that teachers need to be careful with socially vulnerable children, such as children with a low perceived social acceptance as they seem to be negatively affected by a single bout of support.

The lack of effect of parent support was not expected and surprising. As parents are the primary caregivers, activation of the internalized representation of the parent-child relationship should have raised feelings of security and thus have protective effect on WM performance. However, the fact that the study was conducted within a school context 
may have influenced the results. The support of the teacher may have been more expected because the experiment was conducted at school and because of that may have had a stronger effect. Additionally, research shows that older children might experience (parental) support differently from younger children and that they experience support from different individuals in a particular way, depending on the contexts. For example, Seibert and Kerns (2009) showed that in the case of stressful situations within the school context, children (aged 7-12) would look for support with peers rather than with parents. Similarly, a study of Vandevivere, Braet and Bosmans (2015) suggests that only $8 \%$ of early adolescents (10-12 year olds) would specifically look for maternal support in the case of social conflicts.

Finally, no moderating effect of the quality of the parent-child or teacher-child relationship was found. This was contradictory to expectations, as a supportive message from a parent or teacher is likely to have more effect when a positive relationship representation is activated. In the case of a positive relationship with the parent or teacher, a supportive message is in line with the child's internal working model, it will activate attachment related schemes, and this will help restore levels of emotional security (Dykas \& Cassidy, 2011). However, in case of a negative relationship with the parent or teacher the supportive message is not in line with the relationship scheme that the child has and the child is likely to interpret the message in a different way (e.g., dismiss the positive social information; Dykas \& Cassidy, 2011). Such a moderation of relationship quality was found in a previous experiment in younger children, where the effect of parent and teacher support depended on the quality of the parent-child relationship (Vandenbroucke et al., 2017a). Our results, with children in middle childhood, do not support this idea, as the effect of parent and teacher support did not depend on relationship quality. This might be due to the fact that older children form relationships with a broader network of people (e.g., larger groups of peers; Fabes et al., 2009; Holmes et al., 2016). As a consequence, their ideas and scripts about relationships are formed based on social interactions with this broader social network (Dykas \& Cassidy, 2011). If children for example have a negative relationship with a parent, but a good relationship with the teacher and their classmates, this might lead to a more balanced script. In other words, the increased variety in social experience might mean that the whole of relationships with parents, teachers, peers and other important social contacts matter, rather than the relationship quality with one specific social partner.

\subsection{Strengths, limitations and suggestions for future research}

The current study provides interesting insights into the role of relational experiences for working memory performance in children. Adding to previous research, this study is one of the few which examined this topic using an experimental approach, providing information on the causality of the relation between social factors and working memory. Additionally, information about the role of peer, parent and teacher influences on working memory in middle childhood is rare and gravely needed. These insights can help us understand when and how we can prevent or intervene in working memory difficulties. Nevertheless, some limitations to this study should be put forward, which may guide future research efforts on the topics addressed in this study.

First, the current study did not include a condition where children were not socially rejected. Adding an inclusion condition would make it easier to interpret the effect of social exclusion on working memory. Additionally, it might be useful to include additional measures that would help interpret how children experienced the social exclusion task. As some children might cognitively reappraise the situation or find the game unimportant, the exclusion task may have had different effects on children's stress levels, feelings and cognitions. Future studies could ask additional questions about the child's experience with the exclusion task or add more objective measures to assess the effect of the social exclusion task, such as physiological measures for arousal or stress (e.g., cortisol, electro dermal activity).

Second, an audio message was used to manipulate support by parents and teachers. Previous research has shown that hearing the voice of the mother triggers the attachment system to a similar extent as physical proximity, as shown by comparable responses in oxytocin and stress levels (Seltzer et al., 2010). It was therefore assumed that an audio message was a good manipulation of relational support to examine the effect on cognitive functions such as working memory. Nevertheless, it is possible that other or stronger manipulations of relational support might be needed to observe an effect on working memory in this age group. Future studies could use an audio message in combination with a photograph of the parent and teacher giving positive and supportive non-verbal signals (e.g., smiling; Ahnert et al., 2013). Alternatively, the support offered by a parent or teacher while physically present should also be examined.

Finally, considering that limited effects of the manipulations were found the correlation between pre- and post-test working memory was rather low (0.57). This indicates that the ranking of the children before and after the manipulations was quite different, suggesting that the children were somehow affected differently by the social exclusion and the audio messages. It is possible that this is due to different responses to the social exclusion. In that case adding a no-exclusion condition would provide more insights. However, it is also possible that there are other variables, falling outside of our current scope, that moderate the effect of the parent and teacher support. Future research could consider variables such as stress reactivity, temperament or coping strategies. It is for example possible that some children do not have successful coping strategies to deal with experiences of social exclusion (e.g., reappraisal of the situation). For these children support of a parent or teacher might have a more pronounced effect then for children who can cope well with such situations on their own.

\section{Conclusion}

Although experiences of social rejection may have negative impacts on children's social and emotional functioning, results of the current study suggest that in general there is no difference in working memory performance before and after a single experience of social exclusion by an unknown peer. Results do indicate that for children who feel socially accepted a supportive teacher can promote working memory performance. However, for children who do not feel socially accepted one moment of support by the teacher can have a negative effect. For these vulnerable children it might be important to pay attention to providing warm and supportive interactions more frequently and consistently throughout the school career in order to boost their confidence. As such, schools should be aware of the importance of social factors for children's cognitive functioning and learning and incorporate actions to assure a positive social environment within the school and classroom contexts.

\section{Funding}

This research did not receive any specific grant from funding agencies in the public, commercial, or not-for-profit sectors.

\section{Appendix A. Content of the supportive audio message}

\section{English}

"Hi! I heard you are participating in a study and have to do all these tasks. Doing this with someone you don't know must be exciting. 
Maybe the tasks are not that easy and you are a little nervous. But you don't need to be. I am absolutely sure that you are doing a good job. Before you know it, you will be finished and you can go back to the classroom. So just continue for a little while and keep trying your best. Than it will all work out just fine! Bye!"

Dutch

"Hallo! Ik heb gehoord dat je meedoet aan een onderzoek en allemaal taakjes moet maken. Zo bij iemand die je niet kent, dat zal wel spannend zijn. En als de taakjes niet zo gemakkelijk zijn, dan ben je misschien wat zenuwachtig. Maar dat is helemaal niet nodig. Ik ben er zeker van dat je het kan en dat je goed bezig bent! Voor je het weet ben je al klaar en kan je terug naar de klas. Dus doe nog even verder en blijf goed je best doen. Dan lukt het wel! Dag!"

\section{References}

Abrams, D., Weick, M., Thomas, D., Colbe, H., \& Franklin, K. M. (2011). On-line ostracism affects children differently from adolescents and adults. British Journal of Developmental Psychology, 29, 110-123. http://dx.doi.org/10.1348/ $026151010 X 494089$.

Ahnert, L., Harwardt-Heinecke, E., Kappler, G., Eckstein-Madry, T., \& Milatz, A. (2012) Student-teacher relationships and classroom climate in first grade: How do they relate to students' stress regulation? Attachment \& Human Development, 14, 249-263.

Ahnert, L., Milatz, A., Kappler, G., Schneiderwind, J., \& Fisher, R. (2013). The impact of teacher-child relationships on child cognitive performance as explored by a priming paradigm. Developmental Psychology, 49, 554-567. http://dx.doi.org/10.1037/ a0031283.

Alloway, T. P. (2006). How does working memory work in the classroom? Educational Research and Reviews, 1(4), 134-139.

Alloway, T. P. (2007). Automated Working Memory Assessment (AWMA). London: Harcourt Assessment.

Alloway, T. P., \& Alloway, R. G. (2010). Investigating the predictive roles of working memory and IQ in academic attainment. Journal of Experimental Child Psychology, 106, 20-29. http://dx.doi.org/10.1016/j.jecp.2009.11.003.

Alloway, T. P., Gathercole, S. E., Kirkwood, H., \& Elliott, J. (2009). The working memory rating scale: A classroom-based behavioral assessment of working memory. Learning and Individual Differences, 19, 242-245. http://dx.doi.org/10.1016/j.lindif.2008.10. 003.

Baddeley, A. (2010). Working memory. Current Biology, 20(4), R136-R140. http://dx.doi. org/10.1016/j.cub.2009.12.014.

Bernier, A., Carlson, S. M., \& Whipple, N. (2010). From external regulation to self-regulation: Early parenting precursors of young children's executive functioning. Child Development, 81, 326-339. http://dx.doi.org/10.1111/j.1467-8624.2009.01. 01397.x.

Busch, R. M., Farrell, K., Ladahl-Medina, K., \& Krikorian, R. (2005). Corsi block-tapping task performance as a function of path configuration. Journal of Clinical Experimental Neuropsychology, 27, 127-134. http://dx.doi.org/10.1080/138033990513681.

Commodari, E. (2013). Preschool teacher attachment and attention skills. Springer Plus, 2, 673-685. http://dx.doi.org/10.1186/2193-1801-2-673.

De Laet, S., Colpin, H., Vervoort, E., Doumen, S., Van Leeuwen, K., Goossens, L., \& Verschueren, K. (2015). Developmental trajectories of children's behavioral engagement in late elementary school: Both teachers and peers matter. Developmental Psychology, 51, 1292-1306. http://dx.doi.org/10.1037/a0039478.

De Smedt, B., Janssen, R., Bouwens, K., Verschaffel, L., Boets, B., \& Ghesquiere, P. (2009). Working memory and individual differences in mathematics achievement: A longitudinal study from first grade to second grade. Journal of Experimental Child Psychology, 103, 186-201. http://dx.doi.org/10.1016/j.jecp.2009.01.004.

De Weerdt, F., Desoete, A., \& Roeyers, H. (2013). Working memory in children with reading and/or mathematical disabilities. Journal of Learning Disabilities, 46, 461-472. http://dx.doi.org/10.1177/0022219412455238.

De Wilde, A., Koot, H. M., \& van Lier, P. A. C. (2016). Developmental links between children's working memory and their social relations with teachers and peers in the early school years. Journal of Abnormal Child Psychology, 44, 19-30. http://dx.doi. org /10.1007/s10802-015-0053-4.

Diamond, A., \& Ling, D. S. (2016). Conclusions about interventions, programs, and approaches for improving executive functions that appear justified and those that, de spite much hype, do not. Developmental Cognitive Neuroscience, 18, 34-48. http://dx. doi.org/10.1016/j.dcn.2015.11.005.

Dykas, M. J., \& Cassidy, J. (2011). Attachment and the processing of social information across the life span: Theory and evidence. Psychological Bulletin, 137, 19-46. http:// dx.doi.org/10.1037/a0021367.

Eurostat (2015). Employment rate of the age group 15-64 by NUTS 2 regions (tgs 00007). Retrieved from http://ec.europa.eu/eurostat/data/database.

Evans, G. W., \& Schamberg, M. A. (2009). Childhood poverty, chronic stress, and adult working memory. PNAS, 106, 6545-6549. http://dx.doi.org/10.1073/pnas. 0811910106

Fabes, R. A., Martin, C. L., \& Hanish, L. D. (2009). Children's behaviors and interactions with peers. Handbook of peer interactions, relationships, and groups (pp. 45-62). New York: Guilford Press.

Gathercole, S. E., Durling, E., Evans, M., Jeffcock, S., \& Stone, S. (2008). Working memory abilities and children's performance in laboratory analogues of classroom activities. Applied Cognitive Psychology, 22, 1019-1037. http://dx.doi.org/10.1002/acp.1407.

Gathercole, S. E., \& Pickering, S. J. (2000). Assessment of working memory in six- and seven-year-old children. Journal of Educational Psychology, 92, 377-390. http://dx. doi.org/10.1037/0022-0663.92.2.377.

Gorrese, A., \& Ruggieri, R. (2013). Peer attachment and self-esteem: A meta-analytic review. Personality and Individual Differences, 55, 559-568. http://dx.doi.org/10. 1016/j.paid.2013.04.025.

Harter, S. (1982). The perceived competence scale for children. Child Development, 53, 87-97. http://dx. doi.org/10.2307/1129640.

Hawes, D. J., Zadro, L., Fink, E., Richardson, R., O'Moore, K., Griffiths, B., ... Williams, K. D. (2012). The effects of peer ostracism on children's cognitive processes. European Journal of Developmental Psychology, 9, 599-613. http://dx.doi.org/10.1080/ 17405629.2011 .638815

Hazel, N. A., Oppenheimer, C. W., Technow, J. R., Young, J. F., \& Hankin, B. L. (2014). Parent relationship quality buffers against the effects of peer stressors on depressive symptoms from middle childhood to adolescence. Developmental Psychology, 50, 2115-2123. http://dx.doi.org/10.1037/a0037192.

Holmes, C. J., Kim-Spoon, J., \& Deater-Deckard, K. (2016). Linking executive function and peer problems from early childhood through middle adolescence. Journal of Abnormal Child Psychology, 44, 31-42. http://dx.doi.org/10.1007/s10802-0150044-5.

Hughes, J. N. (2011). Longitudinal effects of teacher and student perceptions of teacher-student relationship qualities on academic adjustment. The Elementary School Journal, 112, 38-60. http://dx.doi.org/10.1086/660686.

IBM Corp (2016). IBM SPSS statistics for Windows, version 24.0. Armonk, NY: IBM Corp.

Kelly, M., McDonald, S., \& Rushby, J. (2012). All alone with sweaty palms. Physiological arousal and ostracism. International Journal of Psychophysiology, 83, 309-314. http:// dx.doi.org/10.1016/j.iipsycho.2011.11.008.

Kim, C., Kroger, J. K., Calhoun, V. D., \& Clark, V. P. (2015). The role of the frontopola cortex in manipulation of integrated information in working memory. Neuroscience Letters, 595, 25-29. http://dx.doi.org/10.1016/j.neulet.2015.03.044.

Lafko, N., Murray-Close, D., \& Shoulberg, E. K. (2015). Negative peer status and relational victimization in children and adolescents: The role of stress physiology. Journal of Clinical Child \& Adolescent Psychology, 44, 405-416. http://dx.doi.org/10.1080/ 15374416.2013 .850701$.

Lenartowicz, A., \& Mcintosh, A. R. (2005). The role of anterior cingulate cortex in working memory is shaped by functional connectivity. Journal of Cognitive Neuroscience, 17, 1026-1042. http://dx.doi.org/10.1162/0898929054475127.

Mcquade, J. D., Murray-Close, D., Shoulberg, E. K., \& Hoza, B. (2013). Working memory and social functioning in children. Journal of Experimental Child Psychology, 115, 422-435. http://dx.doi.org/10.1016/j.jecp.2013.03.002.

Milner, B. (1971). Interhemispheric differences in the localization of psychological processes in man. British Medical Bulletin, 27, 272-277.

Mishna, F., Khoury-Kassabri, M., Schwan, K., Wiener, J., Craig, W., Beran, T., ... Daciuk, J. (2016). The contribution of social support to children and adolescents' self-perception: The mediating role of bullying victimization. Children and Youth Services Review, 63, 120-127. http://dx.doi.org/10.1016/j.childyouth.2016.02.013.

Morrison, A. B., \& Chein, J. M. (2011). Does working memory training work? The promise and challenges of enhancing cognition by training working memory. Psychonomic Bulletin \& Review, 18, 46-60. http://dx.doi.org/10.3758/s13423-010-0034-0.

Psouni, E., Di Folco, S., \& Zavattini, G. C. (2015). Scripted secure base knowledge and its relation to perceived social acceptance and competence in early middle childhood. Scandinavian Journal of Psychology, 56, 341-348. http://dx.doi.org/10.1111/sjop. 12208.

Riggs, N. R., Jahromi, L. B., Razza, R. P., Dillworth-Bart, J. E., \& Mueller, U. (2006). Executive function and the promotion of social-emotional competence. Journal of Applied Developmental Psychology, 27, 300-309. http://dx.doi.org/10.1016/j.appdev. 2006.04.002.

Roorda, D. L., Koomen, H. M. Y., Spilt, J. L., \& Oort, F. J. (2011). The influence of af fective teacher-student relationships on students' school engagement and achievement: A meta-analytic approach. Review of Educational Research, 81, 493-529. http:// dx.doi.org/10.3102/0034654311421793.

Seibert, A. C., \& Kerns, K. A. (2009). Attachment figures in middle childhood. International Journal of Behavioral Development, 33, 347-355. http://dx.doi.org/10.1177/ 0165025409103872.

Seltzer, L. J., Ziegler, T. E., \& Pollak, S. D. (2010). Social vocalizations can release oxytocin in humans. Proceedings of the Royal Society B: Biological Sciences, 277, 2661-2666. http://dx.doi.org/10.1098/rspb.2010.0567.

Spilt, L. J., van Lier, P. A. C., Leflot, G., Onghena, P., \& Colpin, H. (2014). Children's socia self-concept and internalizing problems: The influence of peers and teachers. Child Development, 85, 1248-1256. http://dx.doi.org/10.1111/cdev.12181.

St Clair-Thompson, H., Stevens, R., Hunt, A., \& Bolder, E. (2010). Improving children's working memory and classroom performance. Educational Psychology, 30, 203-219. http://dx.doi.org/10.1080/01443410903509259.

Statistics Belgium (2014). B3. Aantal aangiften en totaal netto belastbaar inkomen per type aangifte en per deciel. Retrieved from https://statbel.fgov.be/nl/themas/ huishoudens/fiscale-inkomens\# panel-12.

Suresh, K. (2011). An overview of randomization techniques: An unbiased assessment of outcome in clinical research. Journal of Human Reproductive Sciences, 4, 8-11. http:// dx.doi.org/10.4103/0974-1208.82352.

Tobia, V., Riva, P., \& Caprin, C. (2017). Who are the children most vulnerable to social exclusion? The moderating role of self-esteem, popularity, and nonverbal intelligence 
on cognitive performance following social exclusion. Journal of Abnormal Child Psychology, 45, 789-801. http://dx.doi.org/10.1007/s10802-016-0191-3.

Valcan, D. S., Davis, H., \& Pino-Pasternak, D. (2017). Parental behaviors predicting early childhood executive functions: A meta-analysis. Educational Psychology Review. http://dx.doi.org/10.1007/s10648-017-9411-9.

Van Noordt, S. J. R., White, L. O., Wu, J., Mayes, L. C., \& Crowley, M. J. (2015). Social exclusion modulates event-related frontal theta and tracks ostracism distress in children. NeuroImage, 118, 248-255. http://dx.doi.org/10.1016/j.neuroimage.2015. 05.085 .

Vandenbroucke, L., Spilt, J., Verschueren, K., \& Baeyens, D. (2017a). Keeping the spirits up: The effect of teachers' and parents' emotional support on children's working memory performance. Frontiers in Psychology, 8, 512. http://dx.doi.org/10.3389/ fpsyg. 2017.00512.

Vandenbroucke, L., Verschueren, K., \& Baeyens, D. (2017b). The development of executive functioning across the transition to first grade and its predictive value for academic achievement. Learning and Instruction, 49, 103-112. http://dx.doi.org/10. 1016/j.learninstruc.2016.12.008.

Vandenbroucke, L., Spilt, J., Verschueren, K., Piccinin, C., \& Baeyens, D. (2018). The classroom as a developmental context for cognitive development: a meta-analysis on the importance of teacher-student interactions for children's executive functions. Review of Educational Research, 88, 125-164. http://dx.doi.org/10.3102/ 0034654317743200.

Vandevivere, E., Braet, C., \& Bosmans, G. (2015). Under which conditions do early adolescent needs maternal support? Journal of Early Adolescence, 35, 162-169. http:// dx.doi.org/10.1177/0272431614529364.

Veerman, J. W., Straathof, M. A. E., Treffers, D. A., van den Bergh, B. R. H., \& ten Brink, L. T. (2004). Competentiebelevingsschaal voor kinderen. Amsterdam: Harcourt Test Publishers.

Will, G.-J., van Lier, P. A. C., Crone, E. A., \& Güroğlu, B. (2016). Chronic childhood peer rejection is associated with heightened neural responses to social exclusion during adolescence. Journal of Abnormal Child Psychology, 44, 43-55. http://dx.doi.org/10. 1007/s10802-015-9983-0.

Williams, K. D. (2009). Chapter 6 Ostracism: A temporal need-threat model. In P. Z. Mark (Ed.), Advances in experimental social psychology (Vol. 41, pp. 275-314): Academic Press.

Williams, K. D., Cheung, C. K. T., \& Choi, W. (2000). Cyberostracism: Effects of being ignored over the internet. Journal of Personality and Social Psychology, 79, 748-762. http://dx.doi.org/10.1037/0022-3514.79.5.748. 